\title{
Uber enters medicine but disrupting health care may prove difficult
}

\author{
口 Cite as: CMAJ 2018 June 18;190:E756-7. doi: 10.1503/cmaj.109-5615
}

Posted on cmajnews.com on May 31, 2018.

$\mathrm{T}$ he popular ride-sharing service Uber introduced a program to provide transportation to and from medical appointments, but the complexities of health care could make it a more difficult sector to disrupt than other industries.

Uber Health, so far available only in the United States, allows doctors and hospitals to book rides for patients to attend medical appointments. It has been tested by more than 100 US health facilities, some of which pay for the service to avoid the downstream costs of missed health appointments, particularly in primary care.

The service has been promoted as a cheaper alternative to existing forms of nonemergency transportation, such as taxis. Uber competitor Lyft offers a similar service, called Concierge, and has partnered with medical insurance providers, including Blue Cross Blue Shield.

The US spends an enormous amount of money on health care, much more than countries of similar wealth. According to an international comparison, the US spends $16.9 \%$ of its GDP on health, compared to $10.4 \%$ for Canada and $9.9 \%$ for the United Kingdom. A large portion of that spending, $\$ 3$ billion a year, goes toward non-emergency transportation, according to the Transit Cooperative Research Program, an independent research organization. Medicare and Medicaid cover much of this expense to provide rides for people who either can't afford personal transportation or are unable to drive for health reasons.

About 3.6 million Americans miss medical appointments each year because of transportation difficulties, and the impact of missed primary care appointments is estimated at $\$ 150$ billion annually. Health problems that could have been detected earlier go undiag-
Uber to a city reduces overall per capita ambulance usage by $7 \%$.

However, a study in JAMA Internal Medicine found that the impact of ride-sharing services on medical appointment attendance may be minimal, even if offered for free. Researchers offered free Lyft rides to medical appointments to 786 patients, and the rate of missed appointments was

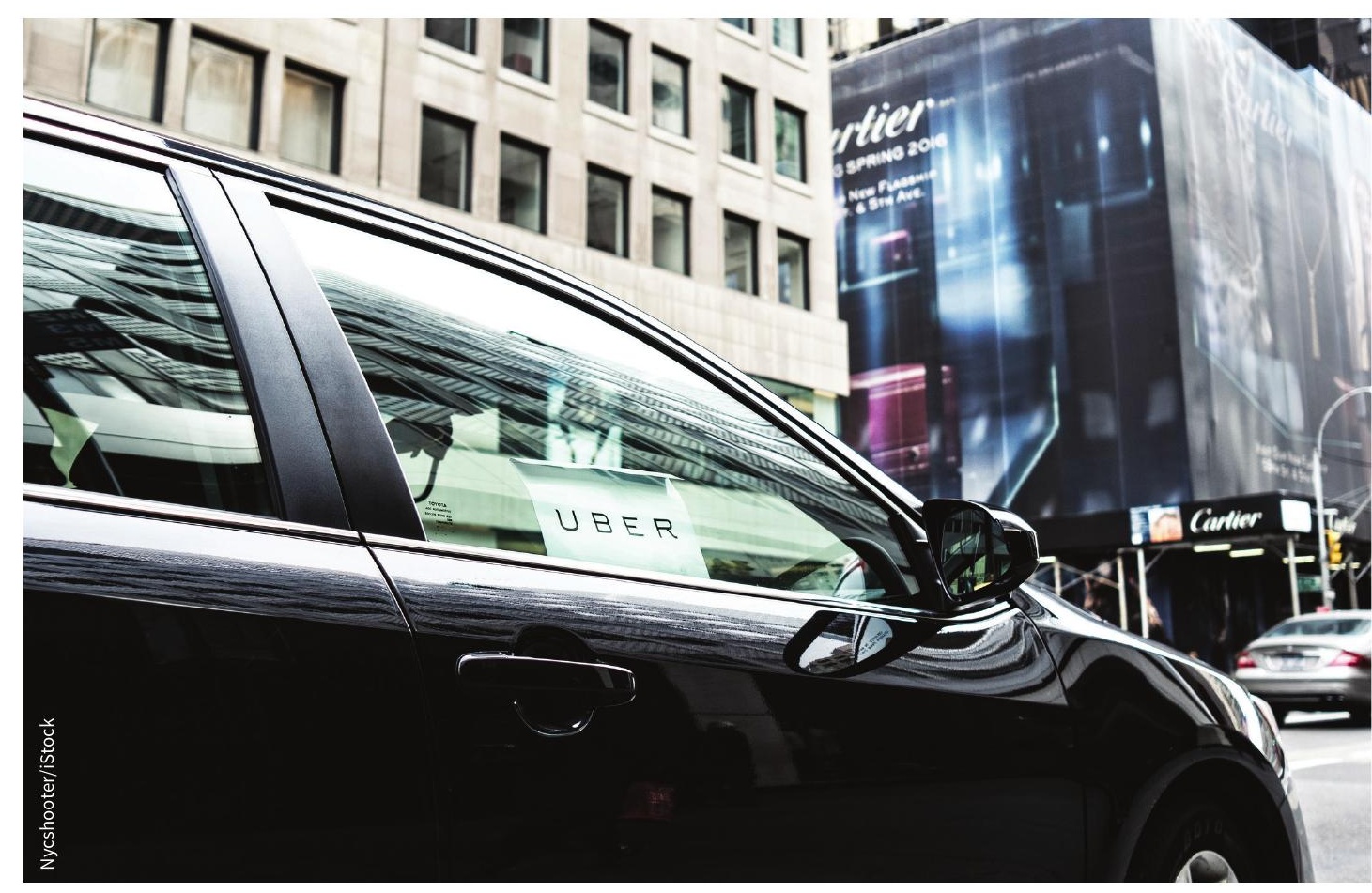

Uber Health is working with doctors and hospitals in the United States to provide patients with rides to medical appointments. nosed, which may lead to more expensive forms of medical care later, such as emergency room visits or extended stays in hospital.

According to one study, the traditional Uber service already diverts low-risk patients from using ambulances. The authors found that the introduction of
$36.5 \%$, nearly identical to the $36.7 \%$ rate among study participants not offered free transportation. More than half of patients contacted with offers of a free ride-sharing service said they weren't interested.

"The uptake of ride-sharing was low and did not decrease missed primary care appointments," the authors concluded. 
"Future studies trying to reduce missed appointments should explore alternative delivery models or targeting populations with stronger transportation needs."

One theory about why ride-sharing may not catch on in health care is that the people most in need of rides, low-income families and older patients, are also among the least tech-savvy and may be skeptical of the service. According to the Pew Research Center, only $15 \%$ of US adults have used ride-sharing services, and $33 \%$ have never heard of them. Ridesharing users tend to be younger, collegeeducated people with high incomes.

Other experts have suggested that disrupting transportation in medicine will be much more difficult than in food delivery or the taxi industry because of the byzantine nature of health care systems that makes radical changes to any aspect of health difficult.

"There are some good reasons why health care has resisted disruption from the outside," Larry Levitt, senior vice president for health reform at the non-profit Kaiser Family Foundation, told Vox. "It operates in a highly regulatory environment. There are complex interactions between insurers, consumers, and health providers that you really don't see in other industries."

Privacy is also a bigger issue in health care than in many other industries. Though
Uber stated that Uber Health is compliant with all US laws about data privacy, critics have noted that the company suffered a data breach in 2016 and 57 million user accounts were affected. Issues around liability for patients who have a medical emergency event in a ride-sharing vehicle have also been raised.

"The burden on the platform and the health-care provider to ensure against something going wrong with the patient is a lot higher than if the patient is calling the car themselves," Arun Sundararajan, author of The Sharing Economy, told The Atlantic.

Roger Collier, CMAJ 